\title{
Potential protection from Alzheimer's disease by wheat germ and rice bran nano-form in rat model
}

\author{
Attia A. Yaseen ${ }^{1}$, Sahar Y. Al-Okbi ${ }^{*}$, Ahmed M. S. Hussein ${ }^{1}$, Doha A. Mohamed², Ayman A. Mohammad ${ }^{1}$, Karem A. Fouda ${ }^{2}$, \\ Fathy M. Mehaya ${ }^{1}$ \\ ${ }^{1}$ Food Technology Department, National Research Centre, Cairo, Egypt. \\ ${ }^{2}$ Nutrition and Food Sciences Department, National Research Centre, Cairo, Egypt.
}

\section{ARTICLE INFO \\ Received on: 04/09/2018 \\ Accepted on: 10/10/2018 \\ Available online: 07/03/2019}

\section{Key words:}

Alzheimer's like model, nano-wheat germ, nano-rice bran, brain biochemistry, butyrylcholinesterase, food chemistry.

\begin{abstract}
The protective effect of nano-wheat germ (NWG) and nano-rice bran (NRB) was evaluated in Alzheimer's like disease (AD) model associated with dyslipidemia in rats. Both NWG and NRB were analyzed for phenolic compounds, fatty acids, tocopherols, and B-vitamins. Plasma lipid profile and butyrylcholinesterase (BChE), brain oxidative stress and inflammatory biomarkers, as well as nutritional parameters, were assessed. The results showed linoleic acid as the major fatty acid while linolenic acid was $<7 \%$ of the total fatty acids. Alpha, gamma, and delta tocopherols were present in both powders; the alpha form was of the highest level. Ferulic, sinapic, and vanillic were the predominant phenolic acids, while rutin and kaempferol were the major flavonoids in both powders. Animal experiment showed the induction of significant dyslipidemia and elevation of plasma $\mathrm{BChE}$ and brain oxidative stress and inflammatory biomarkers in $\mathrm{AD}$ control rats with associated dyslipidemia (AD-DL) compared with normal control. Body weight and food intake were reduced significantly in AD-DL rats compared with normal control. When AD rats were fed on a dyslipidemic diet supplemented with $30 \%$ of either NWG or NRB; all the studied biochemical and nutritional parameters showed significant improvement with different degrees compared with AD-DL control. NWG powder was more promising than NRB.
\end{abstract}

\section{INTRODUCTION}

Alzheimer's disease is amongst the most common neurodegenerative disorders characterized by dementia with affected behavior and cognitive function in elderly and represents a major medical and social burden in both developed and developing countries (Bertram and Tanzi, 2008; Brookmeyer et al., 2007). Alzheimer's disease is usually diagnosed beyond the age of 65 years; however, it may occur at an earlier age due to a mutation in certain genes (Lin and Beal, 2006). It is the fifth cause of death in patients over 65 years old (Subash et al., 2014).

Some metals like aluminum and mercury play a major role in the incidence of Alzheimer's disease (Bonda et al., 2011; Kandimalla et al., 2016). Depositions of amyloid- $\beta$ (A $\beta$ ) protein

*Corresponding Author

Sahar Y. Al-Okbi, Nutrition and Food Sciences Department, National

Research Centre, Cairo, Egypt. E-mail: symmalokbi @ gmail.com

This article was presented at the 5th Euro-Mediterranean Conference and Expo on Life Sciences, Pharma and Biomedicine (BioNat-V), Limassol, Cyprus. in the brain and tau hyperphosphorylation are the main features in Alzheimer's disease which derive from either genetic factors or exposure to the aforementioned metals or both. Chronic treatment of rats by aluminum salt-induced changes in the protein immunecontent pattern of the enzymes involved in the metabolism of tau and amyloid protein leading to high oxidative stress, inflammation, and memory impairment (Prema et al., 2017). Apoptosis was demonstrated in the prefrontal cortex and hippocampal sections stained by hematoxylin and eosin from brains of rats treated by aluminum salts (Olajide et al., 2017) similar to events present in Alzheimer's patients. Patients with vascular or metabolic disorders like dyslipidemia, diabetes, and obesity are more susceptible to Alzheimer's disease than healthy subjects (Madhavadas et al., 2014). High oxidative stress, inflammation, and enhanced choline esterase activity are among the important features in Alzheimer's disease (Al-Okbi et al., 2017). Both acetylcholinesterase and butyrylcholinesterase $(\mathrm{BChE})$ play a pivotal role in the pathogenesis of Alzheimer's disease; where elevated level leads to a reduction 
in the acetylcholine transmitter, which is one of the major causes of the disease (Mushtaq et al., 2014). Epidemiological studies indicate that antioxidant, anti-inflammatory, and neuroprotective agents, including those from health-promoting foods could protect from Alzheimer's disease, possibly through scavenging of reactive oxygen species, cytokine down-regulation, and strengthening the neurons antioxidant defense (Steele et al., 2007). So, it can be hypothesized that consumption of plant foods rich in antioxidant, anti-inflammatory, and lipid-lowering phytochemicals and phytonutrients might serve as protective agent and as an inhibitor of the incidence of Alzheimer's disease. Plant foods like rice bran (RB) and wheat germ (WG), which are the byproducts of wheat milling and rice polishing, respectively, could be good candidates in this respect. This is due to their reported antioxidant, anti-inflammatory, and lipid-lowering activity which was attributed to the presence of different phytochemicals and phytonutrients like phenolic compounds, omega-3 fatty acids, tocopherols, phytosterols, and dietary fibers (Al-Okbi et al., 2013; 2014a; 2014b; Brandolini and Hidalgo, 2012; Kumar and Krishna, 2015). Both WG and RB are bountiful sources of vitamin B. Low intake of folic acid, vitamin B12 and B6, and omega-3 fatty acids is correlated with the incidence of Alzheimer's disease and dementia (Dangour et al., 2010).

WG and RB are good sources of phenolic compounds, especially ferulic acid (FA) and sinapic acid (SA). FA was reported to regulate several key cytoprotective enzymes, such as heme oxygenase-1, inducible nitric oxide synthase, and cyclooxygenase-2 (Mancuso and Santangelo, 2014). This evidence has encouraged researchers to use FA for the treatment of some age-related diseases, such as neurodegenerative disorders and cardiovascular diseases (Barone et al., 2009). Sinapic acid (SA) has neuroprotective activity against kainic acid-induced neuronal damage and possesses a remedial effect towards $A \beta 1-42$ proteinrelated pathology, including neuronal cell death and cognitive dysfunction via its anti-oxidant and anti-inflammatory activities (Kim et al., 2010); therefore, it could be an efficient therapy for Alzheimer's disease (Lee et al., 2012a).

Nanotechnology is a new approach to enhance the bioaccessibility and bioavailability of bioactive compounds in $\mathrm{WG}$ and $\mathrm{RB}$ due to the reduction of the particle size of such ingredients to the nano-scale range. Moreover, the presence of such plant foods byproducts in nano-form might facilitate their transmission through blood-brain barrier to elicit their healthy effect towards Alzheimer's disease brains. The objective of the present research was to evaluate the protective role of nano-rice bran (NRB) and nano-WG (NWG) powder in a rat model of Alzheimer's like disease associated with dyslipidemia. The aim included assessment of tocopherols, B-vitamins, phenolic compounds, and fatty acids in both NRB and NWG.

\section{MATERIALS AND METHODS}

\section{Materials and chemicals}

WG was obtained from the North Cairo Flour Mills Company, Egypt. RB was supplemented by Rice Research and Training Centre, Sakha, Kafr El-Sheikh, Egypt. TAKA-diastase, phenolic compounds, vitamins, and fatty acids standards were purchased from Sigma-Aldrich, Inc. (St-Louis, MO). Aluminum lactate used for induction of Alzheimer's-like disease in rats was brought from Riedel-de Haën, Germany. Acetonitrile and methanol High-performance liquid chromatography (HPLC grade) were purchased from Tedia Company, Inc., Fairfield, OH. Other chemicals were of analytical grade.

\section{Animals}

Male Sprague Dawley rats weighing $127.7 \pm 12.1 \mathrm{~g}$ (Mean $\pm \mathrm{SD}$ ) were used in the present study. Animals were obtained from the Animal House of National Research Centre, Cairo, Egypt. Animals were kept individually in stainless steel cages; water and food were given ad libtium. The animal experiment was carried out according to the Ethics Committee of the National Research Centre, Cairo, Egypt and followed the recommendations of the National Institutes of Health Guide for Care and Use of Laboratory Animals (Publication No. 85-23, revised 1985).

\section{Stabilization of wheat germ and rice bran}

WG and RB were stabilized in an air-oven at a temperature of $120^{\circ} \mathrm{C}$ for 1 minute according to Younas et al. (2011). The stabilized WG and RB were ground using Moulinex grinder, sieved through a 40 -mesh $(420 \mu \mathrm{m})$, packed in polyethylene bags, and stored at $-30^{\circ} \mathrm{C}$ until used.

\section{Preparation of wheat germ and rice bran nano-powders}

WG and RB were ground using $5 \mathrm{~mm}$ zirconium oxide ball and zirconium oxide bowl volume $250 \mathrm{ml}$ in a PM 100 Planetary Ball-mill (Retsch, Germany). Samples (150 g) were ground at $30 \mathrm{~Hz}$ frequency for 60 minutes at room temperature. The particle size of ground samples was examined with Transmission electron microscopy (TEM, JEOL JX 1230, Japan) technique with a micro-analyzer probe. TEM showed that the particle size of WG and $\mathrm{RB}$ was distributed in a range from 7 to $19 \mathrm{~nm}$ and 15 to 47 $\mathrm{nm}$, respectively, which indicated that they are in the nano-scale as reported previously (Mohammad et al., 2015).

\section{Determination of B- vitamins in NWG and NRB}

NWG and NRB were extracted with acid and hydrolyzed using TAKA-diastase as described by Vinas et al. (2003). TAKAdiastase (alfa-amylase) is a form of diastase and used chiefly as a starch digestant. Amounts of $5 \mathrm{~g}$ from each sample were weighed into polypropylene bottles and $25 \mathrm{ml}$ of $0.1 \mathrm{M}$ hydrochloric acid was added. The suspensions were homogenized using an ultrasonic bath for 30 seconds and heated in a water bath at $90^{\circ} \mathrm{C}$ for 30 minutes. The $\mathrm{pH}$ was adjusted to 4 using $1 \mathrm{M}$ sodium acetate; then $0.1 \mathrm{~g}$ of Taka-diastase was added. The sample was maintained in a water bath with magnetic stirring at $50^{\circ} \mathrm{C}$ for 2 hours. Then, 1 $\mathrm{ml}$ of $50 \%$ trichloroacetic acid was added and the bottle was again placed into the water bath at $90^{\circ} \mathrm{C}$ for 10 minutes. The sample was left to cool till it acquires room temperature, then the $\mathrm{pH}$ was adjusted to 6 with $10 \mathrm{M}$ potassium hydroxide and the volume was adjusted to $50 \mathrm{ml}$ using $10 \mathrm{mM}$ potassium dihydrogen phosphate (pH 6). Aliquots were centrifuged at $6,000 \mathrm{rpm}$ for 10 minutes and filtered through a $0.45 \mu \mathrm{m}$ Acrodisc syringe filter (Gelman Laboratory, MI) and analyzed by HPLC. Agilent Technologies 1100 series liquid chromatography equipped with degasser, quaternary pump, autosampler, diode-array, and fluorescence detectors were used. The analytical column was LiChrospher 5 RP Select B $(250 \times 4.0 \mathrm{~mm} ; 5 \mu \mathrm{m})$ with a C18 guard column 
(Phenomenex, Torrance, CA). The B-vitamins were identified and quantified by comparison with standards.

\section{Determination of tocopherols in NWG and NRB}

Samples were saponified according to Lee et al. (2012b). Ground NWG and NRB samples ( $2 \mathrm{~g}$ ) were added to a $15 \mathrm{ml}$ of ethanol containing $6 \%$ pyrogallol in a saponification vessel and vortexed for 30 seconds. After sonication for 5 minutes, $5 \mathrm{ml}$ of potassium hydroxide $(30 \%)$ was added and the vessel was flushed with nitrogen gas for 1 minute. The contents were heated at $70^{\circ} \mathrm{C}$ for 50 minutes in a shaking water bath. After the samples had been cooled for 5 minutes in an ice bath, $20 \mathrm{ml}$ of sodium chloride ( $2 \%$ ) was added, and then vortexed for 30 seconds. The mixture was extracted three times with $50 \mathrm{ml}$ n-hexane: Ethyl acetate extraction solvent (80:20, $\mathrm{v} / \mathrm{v}$ containing $0.1 \mathrm{~g} / \mathrm{l}$ butylated hydroxytoluene). The extracts were collected, diluted to a final volume of $50 \mathrm{ml}$, filtered through a $0.2 \mathrm{~mm}$ filter, and analyzed by HPLC. HPLC apparatus was the same as under B-vitamins but the analytical column was an Eclipse XDB-C18 (150 $\times 4.6 \mu \mathrm{m} ; 5 \mu \mathrm{m})$. Alpha, beta, and gamma tocopherols were identified and quantified by comparison with standards.

\section{Determination of phenolic acid and flavonoids in NRB and NWG}

Phenolic acids were extracted from NWG and NRB and determined according to Kim et al. (2006). Briefly, $1 \mathrm{~g}$ of each sample was placed in a quick fit conical flask and $20 \mathrm{ml}$ of $2 \mathrm{M}$ sodium hydroxide was added and the flasks were flushed with $\mathrm{N}_{2}$ and the stoppers were placed. After shaking the flasks for 4 hours at room temperature; the $\mathrm{pH}$ was adjusted to 2 with $6 \mathrm{M}$ hydrochloric acid. The content of each flask was centrifuged at 5,000 rpm for 10 minutes and the supernatant was collected. Phenolic compounds were extracted twice with $50 \mathrm{ml}$ ethyl ether and ethyl acetate $(1: 1)$. The organic phase was separated and the solvent was evaporated at $45^{\circ} \mathrm{C}$ and the residues were re-dissolved in $2 \mathrm{ml}$ methanol and analyzed by HPLC. HPLC apparatus and the analytical column were the same as under tocopherols. Phenolic acids and flavonoids were identified and calibrated by comparison with standards.
Determination of fatty acid profile of NWG and NRB oils by gas chromatography (GC)

After extraction of the oil from both NRB and NWG by petroleum ether; the fatty acids composition was estimated as methyl esters according to Ludy et al. (1960) using gas chromatography: (Perkin Elmer Auto System XL) with capillary column containing silica ZB-Wax (60 $\mathrm{m} \times 0.32 \mathrm{~mm}$ id) and equipped with flame ionization detector, oven temperature was maintained initially at $50^{\circ} \mathrm{C}$ and programmed from $50^{\circ} \mathrm{C}$ to $220^{\circ} \mathrm{C}$ for 2 minutes at rate, held at $50^{\circ} \mathrm{C}$ to $4^{\circ} \mathrm{C} /$ minute, injector temp $230^{\circ} \mathrm{C}$, detector temp $250^{\circ} \mathrm{C}$ and carrier gas: helium, and flow rate: $1 \mathrm{ml} /$ minute. Fatty acid methyl esters were identified and quantified by comparison of their retention time with authentic standards.

\section{Diets preparation}

Experimental diets were prepared as shown in Table 1. Dyslipidemic diet was prepared according to Zulet et al. (1999). Two test diets (Dyslipidemic diet containing 30\% of either NWG or NRB designated as diet I and II, respectively) and a balanced diet were also prepared.

\section{Induction of Alzheimer's like disease in rats}

A model of Alzheimer's like disease was induced in rats according to the method of Al-Okbi et al. (2017) by intraperitoneal injection of aluminum lactate (as $7.5 \mathrm{mg}$ aluminum $/ \mathrm{kg}$ rat body weight) but there was a modification in the rate of dose and duration of induction which were changed to be four times weekly for 3 weeks. This model was extra modified in the present study through simultaneous induction of dyslipidemia in the same rats by feeding high fat-high cholesterol-bile salt diet for 3 weeks that was assumed to enhance the biochemical changes in Alzheimer's like disease model.

\section{Design of the animal experiment}

Twenty-eight rats were divided into four groups; each of seven rats and assigned to different treatments. Group 1 was served as normal control rats (NC), where rats were fed on a

Table 1. Composition of different experimental diets $(\mathrm{g} / 100 \mathrm{~g})$.

\begin{tabular}{|c|c|c|c|c|}
\hline \multirow{2}{*}{ Ingredients } & \multicolumn{4}{|c|}{ Diets } \\
\hline & Balanced & Dyslipidemic diet & Diet I & Diet II \\
\hline Casein & $12 *$ & $12 *$ & $12 *$ & $12^{*}$ \\
\hline Corn oil & 10 & - & - & - \\
\hline Coconut oil & - & 25 & 25 & 25 \\
\hline Sucrose & 23.5 & 23.5 & 23.5 & 23.5 \\
\hline Starch & 47 & 33.75 & 3.75 & 3.75 \\
\hline Salt mixture & 3.5 & 3.5 & 3.5 & 3.5 \\
\hline Vitamin mixture & 1 & 1 & 1 & 1 \\
\hline Cellulose & 3 & - & - & - \\
\hline Cholesterol & - & 1 & 1 & 1 \\
\hline Bile salt & - & 0.25 & 0.25 & 0.25 \\
\hline NRB & - & - & 30 & - \\
\hline NWG & - & - & - & 30 \\
\hline
\end{tabular}

*12 g casein was estimated to contain $10 \mathrm{~g}$ protein using AOAC (2000).

$\mathrm{NRB}=$ nano-rice bran powder.

$\mathrm{NWG}=$ nano-wheat germ powder. 
balanced diet. Group 2 was served as control Alzheimer's model associated with dyslipidemia (AD-DL), where rats were fed on hypercholesterolemic diet and co-injected intra-peritoneal with aluminum lactate ( $7.5 \mathrm{mg}$ aluminum $/ \mathrm{kg}$ rat body weight) as 4 doses per week. Rats in group 3 were fed on a hypercholesterolemic diet containing $30 \% \mathrm{NRB}$ in addition of aluminum lactate treatment as in group 2. Rats of group 4 were injected with aluminum lactate intraperitoneally just like the previous two groups during feeding on a hypercholesterolemic diet containing 30\% NWG. Body weight and food intake were recorded weekly. At the end of the experiment which continued for 3 weeks, total food intake, body weight gain, and food efficiency ratio (Body weight gain/ total food intake) were calculated. Blood samples were collected from all rats after an overnight fast for determination of plasma total cholesterol (T-Ch) (Watson, 1960), high density lipoprotein cholesterol (HDL-Ch) (Burstein et al., 1980), low density lipoprotein cholesterol (LDL-Ch) (Schriewer et al., 1984), and triglycerides (TG) (Megraw et al., 1979). HDL-Ch/T-Ch ratio was calculated as a determinant of a risk factor for cardiovascular disease. Plasma activity of aspartate transaminase (AST) and alanine transaminase (ALT) were estimated (Reitman and Frankel, 1957) as an indicator of liver function. Plasma creatinine and urea were determined (Fawcett and Scott, 1960; Houot, $1985)$ to assess the kidney function. Plasma BChE activity was estimated according to the method of Vaisi-Raygani et al. (2007). Rats' brains were separated, rinsed with ice-cold saline, and immediately homogenized using phosphate buffer ( $\mathrm{pH}$ 7.4). The homogenates were centrifuged at $4,000 \mathrm{rpm}$ for 10 minutes at $4{ }^{\circ} \mathrm{C}$. The supernatant used for the determination of malondialdehyde (MDA) (Satoh, 1978) as an indicator of lipid peroxidation, tumor necrosis factor- $\alpha$ (TNF- $\alpha)$ as an inflammatory biomarker (Stepaniak et al., 1995), and catalase activity (Aebi, 1984) as an antioxidant.

\section{Statistical analysis}

The results of animal experiments were expressed as the mean \pm SE and they were analyzed statistically using the oneway analysis of variance followed by the Tukey test. In all cases, $p<0.05$ was used as the criterion of statistical significance.

\section{RESULTS}

\section{Fatty acids' composition of NWG and NRB oils}

Fatty acid patterns of NWG and NRB oils are shown in Table 2. Linoleic (omega-6) was the major fatty acids in both oils $(50.77 \%$ and $40.70 \%$ of total fatty acids in NWG and NRB, respectively). In addition, NWG oil contained a reasonable amount $(6.35 \%)$ of linolenic acid (omega-3), whereas, this acid constituted $1.32 \%$ of NRB oil. The monounsaturated fatty acid (oleic, omega-9) represented $23.39 \%$ and $31.0 \%$ for NWG and NRB oils, respectively. Palmitic acid was the only detected saturated fatty acids in NRB oil and amounted $23.74 \%$, whereas it constituted $17.91 \%$ of NWG oil. Palmitoleic and stearic acids were not detected in NWG oil, while stearic and arachidic acids were not detected in NRB oil. Palmitoleic was present as $3.24 \%$ in NRB oil. Arachidic acid was detected in NWG oil in a very low amount $(1.586 \%)$. The ratio of Omega-3/Omega-6 was higher in NWG oil compared with NRB.

\section{Tocopherols and B-vitamins contents of NWG and NRB}

Tocopherol (vitamin E) and B-vitamins contents of NWG and NRB are presented in Table 3. A remarkable high $\mathrm{B}$-vitamins and tocopherols contents were noticed for NWG compared with NRB. The individual components of vitamin "E" in NWG were $178.76,37.93$, and $1.38 \mu \mathrm{g} / \mathrm{g}$ for alpha, gamma, and delta-tocopherol, respectively, while NRB contained 45.60, 6.60 , and $0.66 \mu \mathrm{g} / \mathrm{g}$, respectively. NWG contained abundant components of vitamin B6, B3, and B1 (7.85, 3.40, and 3.11 $\mu \mathrm{g} / \mathrm{g}$, respectively) while it exhibited a lower amount of B2 and B9 $(0.42$ and $0.37 \mu \mathrm{g} / \mathrm{g}$, respectively). NRB contained minor quantities of B1 and B2 compared to B6, while B3 and B9 were not detected.

\section{Different phenolic acids and flavonoids in NWG and NRB}

Phenolic acids profile of NWG and NRB are shown in Table 4. NWG and NRB showed different patterns of phenolic acids. Ferulic acid dominated the phenolic profile in both NWG and NRB being 342.50 and $540.51 \mu \mathrm{g} / \mathrm{g}$, respectively. Sinapic and

Table 2. Fatty acids composition of NWG and NRB oils (as percentage of total fatty acids)

\begin{tabular}{lcc}
\hline Fatty acids & NWG & NRB \\
\hline Palmitic acid (C16:0) & 17.905 & 23.740 \\
Palmitoleic acid (C16:1, n-7) & --- & 3.240 \\
Stearic acid (C18:0) & --- & --- \\
Oleic acid (C18:1, n-9) & 23.386 & 30.995 \\
Linoleic acid (C18:2, n-6) & 50.771 & 40.700 \\
Linolenic acid (C18:3, n3) & 6.350 & 1.320 \\
Arachidic acid (C20:0) & 1.586 & --- \\
SFAs & 19.500 & 23.740 \\
MUFAs & 23.390 & 34.240 \\
PUFAs & 57.120 & 42.020 \\
USFAs & 80.510 & 76.260 \\
Omega-3/Omega-6 & 0.125 & 0.0320 \\
\hline
\end{tabular}

$\mathrm{NRB}=$ nano-rice bran powder; $\mathrm{NWG}=$ nano-wheat germ powder; SFAs = saturated fatty acids; MUFAs = monounsaturated fatty acids; PUFAs = polyunsaturated fatty acids; UFAs $=$ unsaturated fatty acids.

Table 3. Tocopherols and B-vitamins contents of NWG and NRB $(\mu \mathrm{g} / \mathrm{g})$.

\begin{tabular}{lcc}
\hline Vitamin & NWG & NRB \\
\hline Tocopherols & 178.76 & \\
Alpha-tocopherol & 37.93 & 45.60 \\
Gamma-tocopherol & 1.38 & 6.60 \\
Delta-tocopherol & 218.07 & 0.66 \\
Total tocopherol & & 52.86 \\
B-vitamins & 3.11 & \\
Thiamine (B1) & 0.42 & 0.297 \\
Riboflavin (B2) & 3.40 & 0.085 \\
Niacin (B3) & 7.85 & ND \\
Pyridoxine (B6) & 0.37 & 1.131 \\
Folic acid (B9) & ND \\
\hline
\end{tabular}

$\mathrm{NRB}=$ nano-rice bran powder; $\mathrm{NWG}=$ nano-wheat germ powder 
syringic acid were found to be about two- and three-fold in NWG more than NRB, being 182.72 and $64.6 \mu \mathrm{g} / \mathrm{g}$ in NWG and 77.47 and $20.40 \mu \mathrm{g} / \mathrm{g}$ in NRB, respectively. Also, concerning flavonoids, NWG was found to have more rutin, apigenin-7-glucoside, quercetin, and chyrsin than NRB. On the other hand, NRB was

Table 4. Phenolic acids and flavonoids $(\mu / \mathrm{g})$ in NWG and NRB.

\begin{tabular}{|c|c|c|}
\hline Compound & NWG & NRB \\
\hline \multicolumn{3}{|l|}{ Phenolic acids } \\
\hline Protocatechuic acid & ND & 14.32 \\
\hline p-hydroxybenzoic acid & 13.02 & 60.23 \\
\hline Caffeic acid & 2.85 & 8.03 \\
\hline Syringic acid & 64.46 & 20.40 \\
\hline Vanillic acid & 71.96 & 79.98 \\
\hline Ferulic acid & 342.50 & 540.51 \\
\hline Sinapic acid & 182.72 & 77.47 \\
\hline p-coumaric acid & 8.09 & 16.92 \\
\hline Rosmarinic acid & 6.53 & 16.42 \\
\hline Cinnamic acid & 9.14 & 20.28 \\
\hline \multicolumn{3}{|l|}{ Flavonoid compounds } \\
\hline Apigenin-7-glucoside & 9.10 & 1.84 \\
\hline Myricetin & 3.44 & 5.79 \\
\hline Rutin & 48.41 & 24.52 \\
\hline Quercetin & 4.98 & 3.13 \\
\hline Kaempferol & 12.06 & 35.50 \\
\hline Chrysin & 29.91 & ND \\
\hline
\end{tabular}

$\mathrm{NRB}=$ nano-rice bran powder; $\mathrm{NWG}=$ nano-wheat germ powder. found to contain higher protocatechuic, $p$-hydroxybenzoic, caffeic, $p$-coumaric, rosmarinic, and cinnamic acids, as well as kaempferol and myricetin compared with NWG.

\section{Biological evaluation}

The analyzed biochemical parameters of different experimental groups are shown in Table 5. Rats of control AD-DL showed a significant elevation in total cholesterol, triglycerides, LDL-cholesterol, and the ratio of T-Ch/HDL-Ch which is accompanied by significant reduction in the plasma level of HDL$\mathrm{Ch}$ when compared with $\mathrm{NC}$ rats. Intake of a dyslipidemic diet containing either NRB or NWG to rats treated with aluminum lactate improved plasma lipid profile significantly compared with AD-DL control group with different degrees. Diet containing NWG produced significant improvements in lipid parameters compared with NRB containing diet.

Plasma BChE showed a significant elevation in rats of $\mathrm{AD}-\mathrm{DL}$ control compared with NC. Rats fed on a diet containing $\mathrm{NRB}$ or NWG showed a reduction in plasma $\mathrm{BChE}$ significantly compared with AD-DL control group. The levels of TNF- $\alpha$, MDA, and catalase increased significantly in brain tissue of $\mathrm{AD}-\mathrm{DL}$ control rats compared with $\mathrm{NC}$ rats; while feeding a diet containing either NRB or NWG produced a significant improvement of these parameters towards normal levels. NWG diet elicited significant improvement of different brain parameters and plasma BChE compared with NRB diet. Liver and kidney function showed non-significant changes in all the studied groups.

Nutritional parameters of different experimental groups are demonstrated in Figure 1. All nutritional parameters (Final body weight, body weight gain, total food intake, and food efficiency ratio) of $\mathrm{AD}-\mathrm{DL}$ control rats showed a significant severe reduction compared with NC rats. Intake of a diet containing either NRB

Table 5. Biochemical parameters of different experimental groups.

\begin{tabular}{lcccc}
\hline Parameters & \multicolumn{4}{c}{ Groups } \\
\cline { 2 - 5 } & NC & AD-DL & NRB & NWG \\
\hline Plasma parameters & & & \\
T-Ch (mg/dl) & $72.6^{\mathrm{a}} \pm 1.76$ & $124.4^{\mathrm{d}} \pm 4.66$ & $108.2^{\mathrm{c}} \pm 2.06$ & $97.6^{\mathrm{b}} \pm 3.30$ \\
TG (mg/dl) & $72.2^{\mathrm{a}} \pm 1.45$ & $205.9^{\mathrm{d}} \pm 5.34$ & $166.7^{\mathrm{c}} \pm 4.34$ & $123.3^{\mathrm{b}} \pm 7.78$ \\
HDL-Ch (mg/dl) & $41.4^{\mathrm{a}} \pm 0.56$ & $25.3^{\mathrm{d}} \pm 0.60$ & $32.4^{\mathrm{c}} \pm 0.72$ & $36.4^{\mathrm{b}} \pm 0.78$ \\
LDL-Ch (mg/dl) & $20.9^{\mathrm{a}} \pm 0.47$ & $111.7^{\mathrm{d}} \pm 2.49$ & $69.1^{\mathrm{c}} \pm 1.48$ & $54.4^{\mathrm{b}} \pm 2.39$ \\
T-Ch/HDL-Ch & $1.8^{\mathrm{a}} \pm 0.04$ & $4.9^{\mathrm{d}} \pm 0.25$ & $3.4^{\mathrm{c}} \pm 0.11$ & $2.7^{\mathrm{b}} \pm 0.10$ \\
AST (IU/l) & $54.29^{\mathrm{a}} \pm 1.21$ & $56.29^{\mathrm{a}} \pm 1.49$ & $55.71^{\mathrm{a}} \pm 1.46$ & $55.29^{\mathrm{a}} \pm 1.55$ \\
ALT (IU/l) & $40.57^{\mathrm{a}} \pm 1.06$ & $42.86^{\mathrm{a}} \pm 0.77$ & $41.14^{\mathrm{a}} \pm 0.74$ & $41.00^{\mathrm{a}} \pm 0.53$ \\
Urea (mg/dl) & $27.57^{\mathrm{a}} \pm 1.17$ & $28.86^{\mathrm{a}} \pm 0.91$ & $28.29^{\mathrm{a}} \pm 0.75$ & $28.00^{\mathrm{a}} \pm 0.84$ \\
Creatinine(mg/dl) & $0.64^{\mathrm{a}} \pm 0.02$ & $0.67^{\mathrm{a}} \pm 0.03$ & $0.65^{\mathrm{a}} \pm 0.02$ & $0.64^{\mathrm{a}} \pm 0.03$ \\
BChE (U/l) & $172.3^{\mathrm{a}} \pm 4.00$ & $220.0^{\mathrm{d}} \pm 2.47$ & $206.4^{\mathrm{c}} \pm 2.25$ & $191.7^{\mathrm{b}} \pm 2.68$ \\
Brain tissue & & & & $262.8^{\mathrm{b}} \pm 7.80$ \\
Catalase (U/g) & $224.9^{\mathrm{a}} \pm 7.56$ & $351.3^{\mathrm{d}} \pm 10.32$ & $314.5^{\mathrm{c}} \pm 6.32$ & $12.7^{\mathrm{b}} \pm 0.59$ \\
MDA (nmol/g) & $10.6^{\mathrm{a}} \pm 0.60$ & $16.1^{\mathrm{d}} \pm 0.83$ & $13.2^{\mathrm{b}} \pm 0.57$ & $57.6^{\mathrm{b}} \pm 1.98$ \\
TNF- $\alpha(\mathrm{pg} / \mathrm{mg})$ & $38.7^{\mathrm{a}} \pm 1.61$ & $80.0^{\mathrm{d}} \pm 2.81$ & $66.3^{\mathrm{c}} \pm 1.92$ & \\
\hline
\end{tabular}

In each row, same letters mean non-significant difference while different letters mean significant difference at $p<0.05$.

$\mathrm{NC}=$ normal control; AD-DL = control Alzheimer's group fed on dyslipidemic diet; NRB = Alzheimer's group fed on dyslipidemic diet containing $30 \%$ nano-rice bran; NWG = Alzheimer's group fed on dyslipidemic diet containing 30\% nano-wheat germ. 

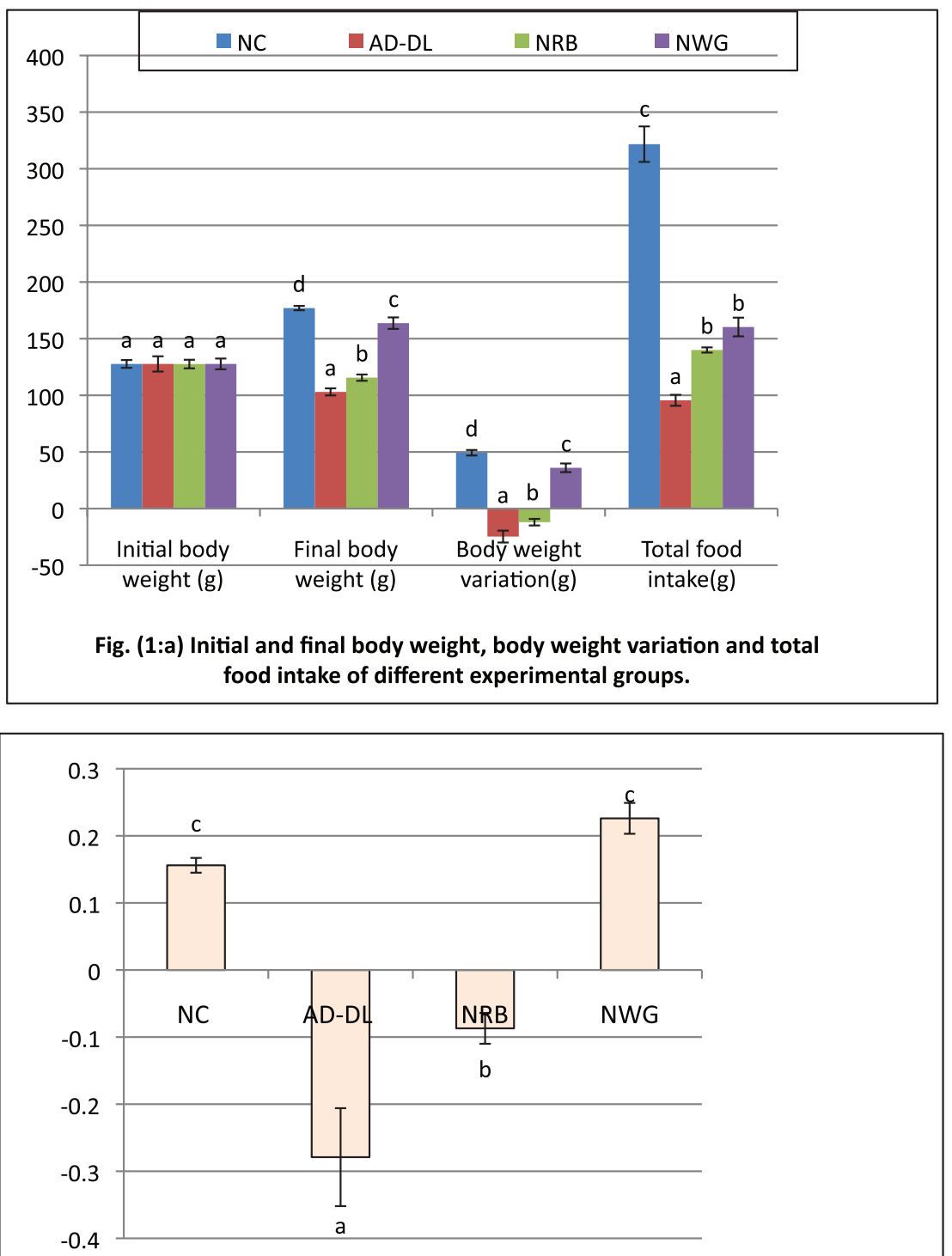

Fig. (1:b) Food efficiency ratio of different experimental groups

Figure 1. Nutritional parameters of different experimental groups. Different letter within a parameter means significant difference at $p<0.05$. $\mathrm{NC}=$ normal control; $\mathrm{AD}-\mathrm{DL}=$ control Alzheimer's group fed on dyslipidemic diet; NRB = Alzheimer's group fed on dyslipidemic diet containing $30 \%$ nano-rice bran; NWG $=\mathrm{Alzheimer}$ 's group fed on dyslipidemic diet containing $30 \%$ nano-wheat germ.

or NWG to $\mathrm{AD}$ rats showed a significant improvement in the nutritional parameters; NWG was more promising in this concern.

\section{DISCUSSION}

The protective effect of NRB and NWG towards rat' Alzheimer's model was demonstrated during the current work, with superiority to NWG. However, the biochemical changes were still not matching the normal level pointing to non-complete protection.

Dys-regulation of metal ion homeostasis has been assumed as one of the key factors in the progression of neurodegenerative diseases. Knowledge of the mechanism underlying metal regulation in the nervous system is important as a way to counteract their harmful effect towards nervous system. Metals' homeostasis is complex with multilayered pathways and they have neuromodulatory roles due to receptors binding (Christofides et al., 2018). A major role of aluminum as a neurotoxic element in the progression of Alzheimer's disease was reported previously (Justin et al., 2017). Aluminum (Al) caused the piling up of tau protein and $A \beta$ protein in the brain of experimental animals and encouraged neuronal apoptosis in vivo and in vitro, either by endoplasmic stress or mitochondrial dysfunction, or integration of them (Kandimalla et al., 2016). High doses of $\mathrm{Al}$ cause deposition of amyloids in the central 
nerve cells (Castorina et al., 2010). So, Al administration in several ways has been used to produce Alzheimer's disease model to search new therapies for such disease. Tanino et al. (2000) demonstrated the induction of Alzheimer's disease model in rats by treatment with aluminum lactate. It was also reported that $7.5 \mathrm{mg} \mathrm{Al} / \mathrm{kg}$ rat body weight from aluminum lactate as the daily intraperitoneal dose was sufficient to induce Alzheimer's disease model in rats weighing $194 \mathrm{~g}$ (Al-Okbi et al., 2017). So, in the present study, Alzheimer's like disease was induced in rats by intraperitoneal injection with aluminum $(7.5 \mathrm{mg} / \mathrm{kg}$ rat body weight) as reported by Al-Okbi et al. (2017) but the dose was four times weekly due to some observed death which could be due to using rats of lower body weights (127.7 g) and/ or feeding dyslipidemic diet. Bad dietary habits that lead to metabolic syndrome play an important role in the development and progression of Alzheimer's disease (Madhavadas et al., 2014). It was reported that hypertriglyceridemia was associated with cerebral amyloidosis in elderly (Choi et al., 2016) which is a feature of Alzheimer's disease. Also, elevated levels of LDL-Ch have the potential to increase the risk of developing Alzheimer's disease (Dias et al., 2015). Vascular diseases and hypercholesterolemia were reported as risk factors for the progression of Alzheimer's disease (Casserly and Topol, 2004; Tamaoka, 2016). For this reason, rats were fed on a hypercholesterolemic diet along with $\mathrm{Al}$ treatment in the present research to enhance the progression of Alzheimer's disease model. The hypercholesterolemic diet-induced dyslipidemia (Increased T-Ch, TG, and LDL-Ch with a reduction in HDL-Ch) resulting in an increase in the T-Ch/HDL-Ch ratio pointed to the high risk of cardiovascular disease in the present model. Also, the hypercholesterolemic diet would have a synergistic effect with aluminum to induce inflammation and high oxidative stress as could be seen from the increased level of brain TNF- $\alpha$ and MDA, respectively, in the present study. These changes along with the increased activity of BChE simulate the biochemical changes reported in Alzheimer's disease in human (Akiyama et al., 2000; Pratico et al., 2000). So, the present animal model succeeded to induce Alzheimer's like disease in rats that could be through the accumulation of Al in brain and dyslipidemia.

The elevation in oxidative stress in brain tissue observed in the present study due to aluminum treatment is in agreement with the results of Bitra et al. (2014) and Justin et al. (2017). Oxidative stress in the brain tissue was reflected in the elevation of MDA as an indicator of enhanced lipid peroxidation in the present study. There is a growing body of evidence that support a role of oxidative stress in Alzheimer's disease reflected in the increased lipid peroxidation and DNA and protein oxidation products in AD brains (Smith et al., 2007). The activity of catalase was increased significantly in the brain of AD model in the present study which might be a compensatory mechanism to counteract the elevated hydrogen peroxide since catalase could reduce the toxic effect of hydrogen peroxide by decomposition into water and oxygen (Mates, 2000). The oxidative stress and inflammatory process result ultimately in a disruption of neuronal cell functioning and signaling, leading to neuronal cell death.

In the present study, $\mathrm{Al}$ induced inflammation in the brain tissue as observed by elevation of TNF- $\alpha$. In Alzheimer's disease, neuro-inflammation plays an important role in the progression and pathogenesis of $\mathrm{AD}$. A wide spectrum of proinflammatory cytokines, such as TNF- $\alpha$ and IL- $1 \beta$ have been considered to play a critical role in neuro-degeneration leading to AD (Jayant et al., 2016; Michaud et al., 2013; Tuppo and Arias, 2005).

The increase in plasma BChE in the present Alzheimer's disease model pointed to the reduction in acetylcholine that observed in Alzheimer's patients. Like acetylcholinesterase, BChE is involved in the hydrolysis of the transmitter acetylcholine, so it is proposed as a potential target in Alzheimer's disease. Inhibitors of plasma BChE were reported to be efficient as anti-Alzheimer's agents (Cherif et al., 2014; Yu et al., 2018).

The model of Alzheimer's like disease in rats used in the present study produced a reduction in all the studied nutritional parameters. Reduction in body weight and negative body weight gain in control rats of AD-DL may be attributed to the reduction of skeletal muscle and decreased oral or swallowing function as found in Alzheimer's disease patients (Takagi et al., 2016).

Phytochemicals derived from plant food are known to exhibit a variety of biological effects, including antioxidant, hypocholesterolemic, anti-inflammatory, and anti-aging activities. Epidemiological studies elucidate the association between nutrition and cognition which highlights the importance of the type of food in preventing or delaying Alzheimer's disease $\mathrm{CH}$ et al., 2013; Pasinetti et al., 2011). Phytochemicals may be good preventive agents in Alzheimer's disease.

In the present study, $\mathrm{RB}$ and $\mathrm{WG}$, two by-products from cereals, are rich sources of phytochemicals such as phenolic compounds, phytosterols, tocopherols, tocotrienols, policosanol, oryzanol, and dietary fibers. The presence of these phytochemicals possesses antioxidant, anti-inflammatory, and hypocholesterolemic effect. Formulation of RB and WG powders in nano-form in the current study may enhance their bioavailability and facilitate the transition of the bioactive constituents through the blood-brain barrier.

Diets containing NRB and NWG produced improvement in plasma lipid profile and nutritional parameters together with a reduction in oxidative stress and inflammation in the brain. NWG was more efficient than NRB in the protection from hypercholesterolemia and brain oxidative stress and inflammation. Also, NWG was more promising in improving plasma BChE and the nutritional parameters. However, both NRB and WRB could not normalize the different biochemical parameters pointing to their capability only to prevent the continual deterioration of these parameters but not affording complete protection from AD. In a recent study, WG agglutinin showed beneficial effects on the enhancement of the permeability of certain natural agents across the blood-brain barrier (Kuo and Lin, 2015). RB extract improved the impaired mitochondrial function in cell culture of AD model (PC12APPsw cells) through elevation of ATP and respiratory rates, as well as PGC1 $\alpha$ protein levels in PC12APPsw cells. The authors attributed the beneficial effects of $\mathrm{RB}$ to the presence of oryzanols, tocopherols, and tocotrienols (Hagl et al., 2015).

NWG and NRB oils contained unsaturated fatty acids represented by omega-3, omega- 6 , and omega- 9 as could be seen in the result section. The reasonable percentage of unsaturated fatty acids in such oils may play an important role in the prevention and treatment of Alzheimer's disease. Dietary supplementation with omega-3 fatty acids was reported to enhance the regulation of 
neuronal membrane excitability, improve the capacity for neuronal transmission and is significantly associated with a lower risk of Alzheimer's disease (Morris, 2009). The presence of omega-3 fatty acids and B-vitamins in both NRB and NWG could afford synergistic effect that may lead to a reduction of the incidence and progression of Alzheimer's disease (Zandi et al., 2004). WG and RB are good sources of $\alpha-$, gamma-, and delta-tocopherol which possess antioxidant and anti-inflammatory effect (Li et al., 2012; Wells et al., 2010) thereby could protect the brain from oxidative and inflammatory damage.

The beneficial effects of NRB and NWG not only reside in their high contents of unsaturated fatty acids, tocopherols, and B-vitamins but also to phenolic compounds assessed in the current work. These components may serve as dietary antioxidants for scavenging free radicals and as an anti-inflammatory agent which may prevent the occurrence of chronic diseases, including Alzheimer's disease. Lee et al. (2012a) demonstrated that SA attenuated amyloid-beta $(A \beta)$ peptide 1-42 protein-induced hippocampal neuronal cell death. The neuroprotective activity of SA was derived from its anti-apoptotic, anti-inflammatory, and radical scavenging properties. Therefore, those authors suggest new insight into the neuroprotective effect of SA and support as an effective treatment for AD. Sgarbossa et al. (2015) reported that many antioxidant compounds including FA have been demonstrated to protect the brain from $A \beta$ neurotoxicity. Ferulic acid, an antioxidant and anti-inflammatory agent, is capable to inhibit and disaggregate the amyloid structures in the brain of Alzheimer's disease patients. Generally, the phenolic acid and flavonoids pattern in both NRB and NWG in conjunction of tocopherols, omega-3 fatty acids, and vitamin B showed to have a great role in improving the biochemical changes in AD model in the present study. The superiority of NWG on NRB could be attributed to its higher contents of vitamin $\mathrm{B}$, tocopherol, and omega-3/omega-6, as well as the lower particle size (7-19 nm and 15-47 $\mathrm{nm}$ for $\mathrm{WG}$ and $\mathrm{RB}$, respectively). The increased body weight when feeding NWG compared with NRB diet might be attributed to the high content of protein and reduced dietary fibers of WG compared with RB (Mohammad et al., 2015).

\section{CONCLUSION}

NWG and RB provide a protective effect against dyslipidemia, oxidative stress, inflammation, and elevated $\mathrm{BChE}$ in the rat model of Alzheimer's disease with dyslipidemia. NWG was more promising than NRB. The possible mechanism of protection may be related to phytochemicals and phytonutrients, such as B-vitamins, tocopherols, phenolic and unsaturated fatty acids that could have enhanced bioavailability and or transmission through the blood-brain barrier due to their presence in nano-form. It is recommended that the onset and progression of Alzheimer's disease might be inhibited by the intake of either NWG or RB.

\section{ACKNOWLEDGMENTS}

This work was financed by the National Research Centre, Egypt.

\section{CONFLICT OF INTERESTS}

There are no conflicts of interest.

\section{REFERENCES}

Aebi H. Catalase in vitro. Methods Enzymol, 1984; 105:121-6. Akiyama H, Barger S, Barnum S. Inflammation and Alzheimer's disease. Neurobiol Aging, 2000; 21:383-421.

Al-Okbi SY, Ammar NM, Mohamed DA, Hamed IM, Desoky AH, El-Bakry HF, Helal AM. Egyptian rice bran oil: chemical analysis of the main phytochemicals. La Rivista Italiana delle Sostanze Grasse, 2014a; 91:47-58.

Al-Okbi SY, Mohamed DA, Abdel Fatah M, Abdel Aal K, Mohammed SE. Evaluation of plant food extracts in experimental model of Alzheimer's like disease induced by aluminum lactate in rats. J Appl Pharm Sci, 2017; 7:70-6.

Al-Okbi SY, Mohamed DA, Hamed IM, Agoor FS, Ramadan AMA, El-Saed SH, Helal AM. Comparative study on Egyptian rice bran extracted by solvents and supercritical CO2. Adv Food Sci, 2013; 35:23-9.

Al-Okbi SY, Mohamed DA, Hamed TE, Esmail RS. Rice bran oil and pumpkin seed oil alleviate oxidative injury and fatty liver in rats fed high fructose diet. Polish J Food Nutr Sci, 2014b; 64:127-33.

Barone E, Calabrese V, Mancuso C. Ferulic acid and its therapeutic potential as a hormetin for age-related diseases. Biogerontology, 2009; 10:97-108.

Bertram L, Tanzi RE. Thirty years of Alzheimer's disease genetics: the implications of systematic meta-analyses. Nat Rev Neurosci, 2008; 9:768-78.

Bitra VR, Rapaka D, Mathala N, Akula A. Effect of wheat grass powder on aluminum induced Alzheimer's disease in Wistar rats. Asian Pac J Trop Med, 2014; 7 S1:278-81.

Bonda DJ, Lee HG, Blair JA, Zhu X, Perry G, Smith MA. Role of metal dyshomeostasis in Alzheimer's disease. Metallomics, 2011; $3: 267-70$.

Brandolini A, Hidalgo A. Wheat germ: not only a by-product. Int J Food Sci Nutr, 2012; 1:71-4.

Brookmeyer R, Johnson E, Ziegler-Graham K, Arrighi HM Forecasting the global burden of Alzheimer's disease. Alzheimers Dement 2007; 3:186-91.

Burstein M, Scholnick HR, Morfin R. Rapid method for the isolation of lipoproteins from human serum by precipitation with polyanions. Scand J Clin Lab Invest, 1980; 40:583-95.

Casserly I, Topol E. Convergence of atherosclerosis and Alzheimer's disease: inflammation, cholesterol, and misfolded proteins. Lancet, 2004; 363:1139-46.

Castorina A, Tiralongo A, Giunta S, Luisa Carnazza M, Scapagnini G. Early effects of aluminum chloride on beta-secretase mRNA expression in a neuronal model of b-amyloid toxicity. Cell Biol Toxicol, $2010 ; 26: 367-77$

Cherif O, Allouche F, Chabchoub F, Chioua M, Soriano E, Yañez M, Cacabelos R, Romero A, López MG, Marco-Contelles J. Isoxazolotacrines as non-toxic and selective butyrylcholinesterase inhibitors for Alzheimer's disease. Future Med Chem, 2014; 6(17):1883-91.

Choi HJ, Byun MS, Yi D, Choe YM, Sohn BK, Baek HW, Lee JH, Kim HJ, Han JY, Yoon EJ, Kim YK, Woo JI, Lee DY. Association between serum triglycerides and cerebral amyloidosis in cognitively normal elderly. Am J Geriatr Psychiatry, 2016; 24(8):604-12.

Christofides K, Menon R, Jones CE. Endocytosis of G proteincoupled receptors and their ligands: Is there a role in metal trafficking? Cell Biochem Biophys, 2018; 76(3):329-37.

Dangour AD, Whitehouse PJ, Rafferty K, Mitchell SA, Smith L, Hawkesworth S, Vellas B. B-vitamins and fatty acids in the prevention and treatment of Alzheimer's disease and dementia: a systematic review. J Alzheimers Dis, 2010; 22:205-24.

Dias HK, Brown CL, Polidori MC, Lip GY, Griffiths HR. LDLlipids from patients with hypercholesterolaemia and Alzheimer's disease are inflammatory to microvascular endothelial cells: mitigation by statin intervention. Clin Sci (Lond), 2015; 129:195-206. 
Fawcett JK, Scott JE. A rapid and precise method for the determination of urea. J Clin Pathol, 1960; 13:156-9.

Hagl S, Grewal R, Ciobanu I, Helal A, Khayyal MT, Muller WE, Eckert GP. Rice bran extract compensates mitochondrial dysfunction in a cellular model of early Alzheimer's disease. J Alzheimers Dis, 2015; 43:927-38.

Houot O. Kinetic determination of creatinine. In: Henny J, Siest G, Schiele F, Young DS (eds.). Interpretation of clinical laboratory tests. Biomedical Publications, California, pp 220-34, 1985.

Hu N, Yu JT, Tan L, Wang YL, Sun L, Tan L. Nutrition and the risk of Alzheimer's disease. Biomed Res Int, 2013; doi: 10.1155/2013/524820

Jayant S, Sharma BM, Sharma B. Protective effect of transient receptor potential vanilloid subtype 1 (TRPV1) modulator, against behavioral, biochemical and structural damage in experimental models of Alzheimer's disease. Brain Res, 2016; 1642:397-408.

Justin TA, William TR, Manivasagam T, Janakiraman U, Mohamed EM. Hesperidin ameliorates cognitive dysfunction, oxidative stress and apoptosis against aluminium chloride induced rat model of Alzheimer's disease. Nutr Neurosci, 2017; 20(6):360-8.

Kandimalla R, Vallamkondu J, Corgiat EB, Gill KD Understanding aspects of aluminum exposure in Alzheimer's disease development. Brain Pathol, 2016; 26:139-54.

Kim KH, Tsao R, Yang R, Cui SW. Phenolic acid profiles and antioxidant activities of wheat bran extracts and the effect of hydrolysis conditions. Food Chem, 2006; 95:466-73.

Kim DH, Yoon BH, Jung WY, Kim JM, Park SJ, Park DH. Sinapic acid attenuates kainic acid-induced hippocampal neuronal damage in mice. Neuropharmacol, 2010; 59:20-30.

Kumar GS, Krishna AG. Studies on the nutraceuticals composition of wheat derived oils wheat bran oil and wheat germ oil. J Food Sci Technol, 2015; 52:1145-51.

Kuo YC, Lin CC. Rescuing apoptotic neurons in Alzheimer's disease using wheat germ agglutinin-conjugated and cardiolipin-conjugated liposomes with encapsulated nerve growth factor and curcumin. Int $\mathrm{J}$ Nanomedicine, 2015; 10:2653-72.

Lee HE, Kim DH, Park SJ, Kim JM, Lee YW, Jung JM, Lee CH, Hong JG, Liu X, Cai M, Park KJ, Jang DS, Ryu JH. Neuroprotective effect of sinapic acid in a mouse model of amyloid $\beta 1-42$ protein-induced Alzheimer's disease. Pharmacol Biochem Behav, 2012a; 103:260-6.

Lee YY, Park HM, Lee CK, Kim SL, Hwang T, Choi MS, Kwon Y, Kim WH, Kim SJ, Lee SC, Kim YH. Comparing extraction methods for the determination of tocopherols and tocotrienols in seeds and germinating seeds of soybean transformed with OsHGGT. J Food Comp Anal, 2012b; 27:70-80.

Li G, Lee MJ, Liu AB, Yang Z, Lin Y, Shih WJ, Yang CS. The antioxidant and anti-inflammatory activities of tocopherols are independent of Nrf2 in mice. Free Radic Biol Med, 2012; 52:1151-8.

Lin MT, Beal MF. Alzheimer's APP mangles mitochondria. Nat Med, 2006; 12:1241-3.

Ludy FE, Barford RA, Riemenschneider RW. Direct conversion of lipid components to their fatty acid methyl esters. J Am Oil Chemists Soc, $1960 ; 37: 447-51$.

Madhavadas S, Kutty BM, Subramanian S. Amyloid beta lowering and cognition enhancing effects of ghrelin receptor analog [D-Lys (3)] GHRP6 in rat model of obesity. Indian J Biochem Biophys, 2014; 51:257-62.

Mancuso C, Santangelo R. Ferulic acid: pharmacological and toxicological aspects. Food Chem Toxicol, 2014; 65:185-95.

Mates M. Effects of antioxidant enzymes in the molecular control of reactive oxygen species toxicology. Toxicol, 2000; 153:83-104.

Megraw R, Dunn D, Biggs H. Manual and continuous flow colorimetry of triglycerols by a fully enzymatic method. Clin Chem, 1979; $25: 273-84$

Michaud M, Balardy L, Moulis G, Gaudin C, Peyrot C, Vellas B, Cesari M, Nourhashemi F. Proinflammatory cytokines, aging, and agerelated diseases. J Am Med Dir Assoc, 2013; 14:877-82.
Mohammad AA, Yousif EI, Yaseen AA, Gdallah MG, Shouk AA, Abdel Fatah AA. Physico-chemical and functional properties of nano and fermented-nano powders of some food plant by-products. Curr Sci Int $2015 ; 4: 503-14$.

Morris MC. The role of nutrition in Alzheimer's disease: epidemiological evidence. Eur J Neurol, 2009; 16:1-7.

Mushtaq G, Greig NH, Khan JA, Kamal MA. Status of acetylcholinesterase and butyrylcholinesterase in Alzheimer's disease and type 2 diabetes mellitus. CNS Neurol Disord Drug Targets, 2014; 13(8):1432-9.

Olajide OJ, Yawson EO, Gbadamosi IT, Arogundade TT, Lambe E, Obasi K, Lawal IT, Ibrahim A, Ogunrinola KY. Ascorbic acid ameliorates behavioural deficits and neuropathological alterations in rat model of Alzheimer's disease. Environ Toxicol Pharmacol, 2017; 50:200-11.

Pasinetti GM, Wang J, Porter S, Ho L. Caloric intake, dietary lifestyles, macronutrient composition, and Alzheimer's disease dementia. Int J Alzheimers Dis, 2011; Available via https://www.hindawi.com/journals/ ijad/2011/806293/; https://www.ncbi.nlm.nih.gov/pubmed/21808725. doi: $10.4061 / 2011 / 806293$

Pratico D, Clark CM, Lee VM. Increased 8, 12-iso-iPF2 $\alpha$ VI in Alzheimer's disease: correlation of a non-invasive index of lipid peroxidation with disease severity. Ann Neurol, 2000; 48:809-12.

Prema A, Justin Thenmozhi A, Manivasagam T, Mohamed Essa M, Guillemin GJ. Fenugreek seed powder attenuated aluminum chlorideinduced tau pathology, oxidative Stress, and inflammation in a rat model of Alzheimer's disease. J Alzheimers Dis, 2017; 60(s1):S209-20.

Reitman S, Frankel S. Colorimetric methods for aspartate and alanine aminotransferase. Am J Clin Path, 1957; 28:55-60.

Satoh K. Serum lipid peroxide in cerebrovascular disorders determined by a new colorimetric method. Clinica Chimica Acta, 1978, 20:37-43.

Schriewer H, Kohnert U, Assmann G. Determination of LDL cholesterol and LDL apolipoprotein B following precipitation of VLDL in blood serum with phosphotungstic acid/ $\mathrm{MgCl} 2$. J Clin Chem Clin Biochem, $1984 ; 22: 35-40$.

Sgarbossa A, Giacomazza D, di Carlo M. Ferulic acid: a hope for Alzheimer's disease therapy from plants. Nutrients, 2015; 7:5764-82.

Smith DG, Cappai R, Barnham KJ. The redox chemistry of the Alzheimer's disease amyloid beta peptide. Biochim Biophys Acta, 2007; 1768:1976-90.

Steele M, Stuchbury G, Münch G. The molecular basis of the prevention of Alzheimer's disease through healthy nutrition. Exp Gerontol, 2007; 42:28-36.

Stepaniak JA, Gould KE, Sun D, Swanborg RH. A comparative study of experimental autoimmune encephalomyelitis in Lewis and DA rats. J Immunol, 1995; 155:2762-9.

Subash S, Essa MM, Al-Asmi A, Al-Adawi S, Vaishnav R, Braidy N, Manivasagam T, Guillemin GJ. Pomegranate from Oman alleviates the brain oxidative damage in transgenic mouse model of Alzheimer's disease. J Tradit Complement Med, 2014; 4:232-8.

Takagi D, Hirano H, Watanabe Y, Edahiro A, Ohara Y, Yoshida H, Kim H, Murakami K, Hironaka S. Relationship between skeletal muscle mass and swallowing function in patients with Alzheimer's disease. Geriatr Gerontol Int, 2016; 17(3):402-9.

Tamaoka A. Dyslipidemia and dementia. Brain Nerve, 2016; 68:737-42.

Tanino H, Shimohama S, Sasaki Y, Sumida Y, Fujimoto S Increase in phospholipase $\mathrm{C}-\delta 1$ protein levels in aluminum-treated rat brains. Biochem Biophys Res Commun, 2000; 271:620-5.

Tuppo EE, Arias HR. The role of inflammation in Alzheimer's disease. Int J Biochem Cell Biol, 2005; 37:289-305.

Vaisi-Raygani A, Rahimi Z, Kharazi H, Tavilani H, Aminiani M, Kiani A, Vaisi-Raygani A, Pourmotabbed T. Determination of butyrylcholinesterase (BChE) phenotypes to predict the risk of prolonged apnea in persons receiving succinylcholine in the healthy population of western Iran. Clin Biochem, 2007; 40:629-33. 
Vinas P, Lopez-Erroz C, Balsalobre N, Hernandez-Cordoba M. Reversed-phase liquid chromatography on an amide stationary phase for the determination of the B group vitamins in baby foods. J Chromatography A, 2003; 1007:77-84.

Watson D. A simple method for the determination of serum cholesterol. Clin Chem Acta, 1960; 5:637-42.

Wells SR, Jennings MH, Rome C, Hadjivassiliou V, Papas KA, Alexander JS. Alpha-, gamma- and delta-tocopherols reduce inflammatory angiogenesis in human microvascular endothelial cells. J Nutr Biochem, 2010; 21:589-97.

Younas A, Bhatti S, Ahmed A, Randhawa MA. Effect of rice bran supplementation on cookie baking quality. Pak J Agric Sci, 2011; 48:129-34.

Yu Z, Wu S, Zhao W, Ding L, Fan Y, Shiuan D, Liu J, Chen F. Anti-Alzheimers activity and molecular mechanism of albumin-derived peptides against AChE and BChE. Food Funct, 2018; 9(2):1173-8.

Zandi PP, Anthony JC, Khachaturian AS, Stone SV, Gustafson D, Tschanz JT, Norton MC, Welsh-Bohmer KA, Breitner JC. Reduced risk of Alzheimer disease in users of antioxidant vitamin supplements: the Cache County Study. Arch Neurol, 2004; 61(1):82-8.

Zulet MA, Macarulla MT, Portillo MP, Noel-Suberville C, HigueretP, MartínezJA. Lipid and glucose utilization in hypercholesterolemic rats fed a diet containing heated chickpea (Ciceraretinum L.): a potential functional food. Int J Vitam Nutr Res, 1999; 69:403-11.

\section{How to cite this article:}

Yaseen AA, Al-Okbi SY, Hussein AMS, Mohamed DA, Mohammad AA, Fouda KA, Mehaya FM. Potential protection from Alzheimer's disease by wheat germ and rice bran nanoform in rat model. J Appl Pharm Sci, 2019; 9(S1):067-076. 